\title{
MULHERES E A HISTÓRIA APRENDIDA NOS LIVROS DIDÁTICOS: ANÁLISE DE COLEÇÕES DIDÁTICAS
}

\author{
Ana Maria Marques \\ Universidade Federal de Mato Grosso (UFMT), Brasil \\ E-mail: anamariamarques.ufmt@gmail.com \\ ORCID: https://orcid.org/0000-0002-4853-8200
}

\author{
Ana Carolina do Nascimento Albuquerque \\ Secretaria Estadual Educação de Mato Grosso (SEED/MT), Brasil \\ E-mail: caroline-c-b@hotmail.com \\ ORCID: https://orcid.org/0000-0003-2011-8746
}

Data de recebimento: 03/02/2020

Data de aprovação: 29/03/2020

DOI: https://doi.org/10.30612/frh.v22i39.12573

Resumo: Este artigo parte do diagnóstico de invisibilidade das mulheres nos livros didáticos de História e aborda a importância de considerar a interseccionalidade de raça e classe nas análises de gênero. Analisa a trajetória de pesquisas sobre livros didáticos, os avanços identificados por meio do PNLD 2018, as indicações do Guia dos Livros Didáticos e duas coleções didáticas: História, Sociedade \& Cidadania e História: das Cavernas ao Terceiro Milênio. Apesar do crescimento dos estudos de gênero, a pesquisa aponta para uma ausência de mulheres e ainda mais do protagonismo delas.

Palavras-chave: mulheres; gênero; História; livros didáticos.

\section{WOMEN AND THE HISTORY LEARNED IN TEXTBOOKS: ANALYSIS OF DIDATIC BOOK COLLECTIONS}

\begin{abstract}
Abbstract: This article starts from the diagnosis of women's invisibility in history textbooks and addresses the importance of considering the intersectionality of race and class in gender analysis. It analyzes the trajectory of research on textbooks, the advances identified through the PNLD 2018, the indications of the Didactic Books Guide and two didactic collections: História, Sociedade \& Cidadania and História: das Cavernas ao Terceiro Milênio. Despite the growth of gender studies, the research points to an absence of women and even more of their role.
\end{abstract}

Keywords: women; genre; History; Didatic books. 


\section{LAS MUJERES Y LA HISTORIA APRENDIDA EN LOS LIBROS DE ENSEÑANZA: ANÁLISIS DE COLECCIONES DE ENSEÑANZA}

Resumen: Este artículo parte del diagnóstico de invisibilidad de las mujeres en los libros didácticos de historia y aborda la importancia de considerar la interseccionalidad de la raza y la clase en el análisis de género. Analiza la trayectoria de la investigación sobre libros de texto, los avances identificados a través del PNLD 2018, las indicaciones de la Guía de libros didácticos y dos colecciones didácticas: História, Sociedade \& Cidadania y História: das Cavernas ao Terceiro Milênio. A pesar del crecimiento de los estudios de género, la investigación apunta a la ausencia de mujeres y aún más de sus protagonismos.

Palabras Clave: mujeres; género; Historia; libros didácticos.

\section{Introdução}

Os indicadores sociais sobre mulheres no Brasil apresentam que, apesar de elas serem maioria com Ensino Superior Completo, têm média salarial inferior aos homens. São as mulheres que dedicam maior parte do tempo aos afazeres domésticos, segundo confirma o Instituto Brasileiro de Geografia e Estatística - IBGE:

No Brasil, em 2016, as mulheres dedicaram aos cuidados de pessoas e/ou afazeres domésticos cerca de $73 \%$ a mais de horas do que os homens $(18,1$ horas contra 10,5 horas). Ao desagregar por região, verifica-se que a maior desigualdade na distribuição de horas dedicadas a estas atividades está na Região Nordeste, onde as mulheres dedicam cerca de $80 \%$ a mais de horas do que os homens, alcançando 19 horas semanais. O recorte por cor ou raça indica que as mulheres pretas ou pardas são as que mais se dedicam aos cuidados de pessoas e/ou aos afazeres domésticos, com o registro de 18,6 horas semanais em 2016. Observa-se que o indicador pouco varia para os homens quando se considera a cor ou raça ou região de residência (IBGE, 2016, p. 3).

Com relação à vida pública e a tomada de decisão, em 20 de dezembro de 2017, $39,1 \%$ dos cargos gerenciais eram ocupados por mulheres, e na câmara dos deputados, apenas $10,5 \%$.

Apesar da existência de cotas, em 20.12.2017, o percentual de cadeiras ocupadas por mulheres em exercício no Congresso Nacional era de 11,3\%. No Senado Federal, composto por eleições majoritárias, $16,0 \%$ dos senadores eram mulheres e, na Câmara dos Deputados, composta por eleições proporcionais, apenas $10,5 \%$ dos deputados federais eram mulheres. Paraíba, Sergipe e Mato Grosso não tinham nenhuma mulher exercendo o cargo de deputada federal na data (IBGE, 2016, p. 9). 
O documento não contempla a representatividade das mulheres negras nos espaços de poder, revelando o impacto causado na vida dessas mulheres pelo racismo estrutural, entendido não como ato isolado de um individuo ou de um grupo, mas como parte da estrutura social. Segundo Silvio de Almeida (2018), o racismo como processo histórico e político, cria as condições sociais para que, direta ou indiretamente, grupos racialmente identificados sejam discriminados de forma sistemática. Ainda que os indivíduos racistas sejam responsabilizados por seus atos, "o olhar estrutural sobre as relações raciais, nos leva a concluir que a responsabilização jurídica não é suficiente para que a sociedade deixe de ser uma máquina produtora de desigualdade racial” (ALMEIDA, 2018, p. 51). O silenciamento sobre a ausência das mulheres negras nos espaços de poder e nas lideranças das instituições públicas e privadas, segundo Silvio Almeida (2018), significa a materialização de uma estrutura social, pois as instituições, cujos padrões de funcionamento privilegiam determinados grupos sociais têm o racismo como parte da ordem social. Ressaltamos que isso não a isenta da responsabilidade. Considerando que a estrutura social é construída, as instituições assim como os indivíduos, também podem posicionar-se contra a naturalização do racismo, implementando práticas antirracistas efetivas.

Entretanto, contraditoriamente, se por um lado há o silenciamento sobre a pouca ou nenhuma representatividade das mulheres negras nos espaços de poder político e no exercício de cargos de comando, quando o assunto são os índices de violência contra as mulheres, as mulheres negras, tragicamente recebem destaque. O Atlas da violência 2019, lançado pelo Instituto de Pesquisa Econômica Aplicada (Ipea) e pelo Fórum Brasileiro de Segurança Pública (FBSP) apresenta um cenário calamitoso de crimes letais contra mulheres, atingindo principalmente as mulheres negras, o que indica um crescimento dos homicídios femininos em 2017. Os dados revelam que em média 13 mulheres foram assassinadas por dia, das quais, $66 \%$ eram negras. Ao todo, 4.936 mulheres foram mortas, o maior número registrado desde 2007. "Enquanto a taxa de homicídios de mulheres não negras teve crescimento de 4,5\% entre 2007 e 2017, a taxa de homicídios de mulheres negras cresceu 29,9\%" (CERQUEIRA et. al., 2019, p. 38). De acordo com as pesquisas, o crescimento muito superior da violência letal entre mulheres negras em comparação com as não negras evidencia a enorme dificuldade que o Estado brasileiro tem de garantir a universalidade de suas políticas públicas. Ao criticar as velhas narrativas, Bell Hooks (2019) sugere formas alternativas de contemplar a negritude, a partir de um novo olhar. Esse novo significa um olhar opositor, de desconstrução, de questionamento, que aprende a olhar como forma de resistência contra o racismo, embasado 
no entendimento ético e político do racismo e da rejeição à dominação de alguém, entendendo que o racismo é opressor, não por que as pessoas brancas têm sentimentos preconceituosas em relação aos negros, mas por que o sistema que promove a opressão, e a dominação é muito lucrativa para alguns.

Considerando o recorte interseccional, partindo do cenário de inferiorização e violências praticadas contra as mulheres nos livros didáticos de História não ajudam muito reverter esses números. Utilizamos nesta pesquisa o livro didático como um documento histórico, sem desconsiderar sua importância enquanto objeto físico de valor comercial. Consideramos também a necessidade de não se ater apenas ao que é apresentado, mas ao que está invisibilizado, sem negligenciar elementos para além do texto principal, que podem ser "reveladores das intenções ideológicas ou pedagógicas dos autores, como as notas de rodapé, os resumos, a formulação dos títulos e subtítulos dos capítulos, os sumários, o léxico, o índex ou, simplesmente, o próprio título dos livros" (CHOPPIN, 2004, p. 559).

O objetivo desse trabalho é refletir sobre a construção do gênero, pensando por que há tão poucas mulheres nos livros didáticos e ainda menos mulheres protagonistas. A análise foi feita a partir de duas coleções didáticas de História para o Ensino Médio, aprovadas pelo Programa Nacional do Livro Didático - PNLD de 2018. São elas: História, Sociedade \& Cidadania, de Alfredo Boulos Júnior (Ed. FTD); e História: das Cavernas ao Terceiro Milênio, de Patrícia Ramos Braick e Myriam Becho Mota (Ed. Moderna).

De acordo com levantamento feito junto ao Fundo Nacional de Desenvolvimento da Educação - FNDE, as duas coleções selecionadas para a pesquisa estão entre as mais distribuídas pelo Plano Nacional do Livro Didático (PNLD) de História a estudantes do Ensino Médio da rede pública de ensino. Dos 89.381.588 exemplares de livros didáticos de História para o Ensino Médio distribuídos pelo PNLD de 2018 aproximadamente 50\% desse total pertence às editoras Moderna, Ática e FTD. As coleções mais distribuídas foram, respectivamente, História, Sociedade \& Cidadania, da editora FTD (1.820.723); História Global, da Editora Saraiva (1.136.038); História: das Cavernas ao Terceiro Milênio, da editora Moderna (1.068.925), e História: Passado e Presente, da editora Ática (556.221).

Além de se destacarem como as mais utilizadas no ensino de história, a escolha das coleções se deu pela avaliação positiva que ambas tiveram no Guia de Livros Didáticos (BRASIL, 2017) quanto à possibilidade de auxiliar no entendimento das mulheres como sujeitos históricos e na discussão dos papéis sociais tradicionalmente atribuídos ao gênero feminino. Enfatizamos que o PNLD de 2018 para o Ensino Médio foi o último licitado e 
aprovado antes da homologação da Base Nacional Comum Curricular (BNCC), que retira a obrigatoriedade da disciplina de História no currículo do Ensino Médio, sendo passível de ser escolhida pelo estudante na forma de itinerário formativo, denominado Ciências Humanas e Sociais Aplicadas, abrindo caminho para possíveis mudanças nos livros didáticos.

Ainda com relação aos motivos da escolha das coleções para análise, observamos a autoria das treze coleções didáticas de História para o Ensino Médio aprovadas pelo PNLD de 2018, e verificamos que cinco apresentaram autoria totalmente masculina, sete com autoria coletiva, com participação de autores e autoras, e apenas a coleção História: das Cavernas ao Terceiro Milênio, de Patrícia Ramos Braick e Myriam Becho Mota, da editora Moderna, com autoria $100 \%$ feminina.

No PNLD de 2015, das 19 coleções aprovadas, duas tinham autoria 100\% feminina: História: das Cavernas ao Terceiro Milênio e Ser Protagonista História, entre as outras, nove eram de autoria masculina e oito coletivas, assinadas por autoras e autores. A partir desses dados, é possível afirmar que as mulheres vêm conquistando espaço na autoria de livros didáticos, apesar de ainda ser um mercado majoritariamente masculino.

Outro aspecto importante a ser destacado sobre as coleções selecionadas para análise nesta pesquisa é a identificação das autoras e autores que os produziram. Desse modo, os próximos parágrafos apresentam quem são essas autoras e autores, com ênfase nas suas formações e atuação profissional.

Alfredo Boulos Junior, autor da Editora FTD, é doutor em Educação pela Pontifícia Universidade Católica de São Paulo. Mestre em Ciências pela Universidade de São Paulo. Atua, principalmente, nos seguintes temas: representação, imagens, africanos, afrodescendentes, livro didático e África. É autor de coleções didáticas de História para o Ensino Médio e Fundamental, e de paradidáticos. Lecionou nas redes pública, particular e em cursinhos pré-vestibulares.

Myriam Becho Mota, autora da Editora Moderna, é licenciada em História pela Faculdade de Ciências Humanas de Itabira, em Minas Gerais (MG). Mestre em Relações Internacionais pela Ohio University dos EUA. Atua como professora do Ensino Médio e Superior em Itabira, MG. Tem experiência na área de História, com ênfase em Culturas Políticas, atuando principalmente nos seguintes temas: Antropologia, Ciência Política, História Contemporânea e História da América. 
Patrícia Ramos Braick é mestre em História (área de concentração: História das Sociedades Ibéricas e Americanas) pela Pontifícia Universidade Católica do Rio Grande do Sul. Atua como professora do Ensino Médio em Belo Horizonte, MG.

As informações do autor e das autoras foram retiradas da Plataforma Lattes e das apresentações dos livros didáticos, no entanto, não foi possível identificar se os Estudos de Gênero influenciaram a formação ou trajetória acadêmica dessas pessoas.

A fim de refletir em que circunstâncias o protagonismo das mulheres é evidenciado, para efeito desta pesquisa compreendemos as mulheres como sujeitos históricos, buscando identificar a discussão dos papéis sociais tradicionalmente atribuídos às mulheres, bem como a superação das violências e desigualdades.

\section{Os usos da categoria gênero e o olhar interseccional}

Ao utilizar o gênero como categoria de análise histórica, nos embasamos na perspectiva de Joan Scott (1995), que reformulou o uso do gênero, pois antes, como ela descreve, era teorizado em caráter limitado, com generalizações redutivas ou demasiadamente simples, baseadas em explicações causais universais. Scott propõe o gênero como categoria de análise histórica e faz um exame crítico dos usos mais comuns do gênero, expondo as limitações e contradições dessas abordagens.

A autora apresenta uma primeira abordagem de gênero que foi, durante muito tempo essencialmente descritiva, referindo-se a existência de fenômenos sem interpretar, explicar ou atribuir causalidade, utilizando o termo gênero como sinônimo de mulher, supostamente dissociado da carga política, para sugerir que o estudo das mulheres implica o estudo dos homens, para designar relações sociais entre os sexos sem nada dizer sobre como e por que essas relações são construídas, para indicar construções culturais impostas sobre os corpos e para distinguir papéis sexuais atribuídos a homens e mulheres.

O uso da categoria gênero, para Scott, é também de ordem causal, sobre a natureza dos fenômenos e das realidades. Para ela, as feministas marxistas, baseadas na exigência da causalidade econômica, consideravam que o gênero não tinha status analítico próprio. A crítica feita às teorizações do feminismo de orientação psicanalítica refere-se à leitura redutiva do gênero, percebido como fixo e previsível, que desconsidera os contextos sociais e históricos, contribuindo para acentuar "a oposição binária entre masculino-feminino como a 
única relação possível e como um aspecto permanente da condição humana" (SCOTT, 1995, p. 83).

A respeito das reflexões feitas por Scott sobre os usos do gênero que não consideraram sua independência epistemológica como categoria de análise histórica, é possível perceber que o uso descritivo e causal do gênero, desconsiderando a relação entre eixos sobre os quais se estruturam as desigualdades, em muitos momentos, reforçou aquilo que se desejava combater: a construção hierárquica da relação entre masculino e feminino. Ao basear a análise na diferença física entre os sexos, e não como um saber construído e relativo a respeito das diferenças percebidas entre os sexos, a partir de disputas políticas, reforçou-se a ideia de que as diferenças eram inerentes e, consequentemente, o pensamento de que as hierarquias também eram, sem entender que "o uso do gênero enfatiza todo um sistema de relações que pode incluir o sexo, mas não é diretamente determinado pelo sexo, nem determina diretamente a sexualidade" (SCOTT, 1995, p. 76).

Neste trabalho, gênero constitui o saber construído socialmente que estabelece significado para as diferenças percebidas entre os sexos, é histórico, flexível e constitutivo de relações sociais, como apresentado por Joan Scott (1995). Ela afirma sua motivação feminista e, portanto, política, ao revelar seu objetivo de apontar e questionar as desigualdades entre homens e mulheres:

Mais do que isso, é uma motivação que as feministas compartilham com os que estão preocupados em modificar a representação de outros grupos deixados fora da história em razão da raça, etnicidade e classe, tanto quanto em razão do gênero. Ainda que sejam fáceis de fazer, essas afirmações são difíceis de implementar, especialmente se nos falta uma análise de como as hierarquias de gênero são construídas, legitimadas, contestadas e mantidas. (SCOTT, 1994, p. 14).

Dessa forma, Scott indica que mais importante do que escrever sobre as mulheres na história, é analisar por que elas foram ignoradas e silenciadas por tanto tempo. Sugere focar nos processos "a respeito de como hierarquias como as de gênero são construídas e legitimadas" (SCOTT, 1994, p. 16).

Para Scott (1994), a história do pensamento feminista é uma história da recusa da construção hierárquica da relação entre masculino e feminino, sendo necessário a rejeição do caráter fixo e permanente dessa oposição binária, historicizando e desconstruindo os termos. Diante da incapacidade das teorias existentes para explicar as persistentes desigualdades entre as mulheres e os homens, Scott propõe o gênero como uma categoria analítica, para em vez da 
busca de origens únicas, da causalidade geral e universal, pensar nos processos, questionando sobre como as coisas se passaram para descobrir por que elas se passaram.

O gênero como forma primária de dar significado às relações de poder implica pensar que está na base das relações desiguais dos campos de força sociais. Segundo Michel Foucault (1989, p. 215), o poder em sua "forma capilar de existir, no ponto em que o poder encontra o nível dos indivíduos, atinge seus corpos, vem se inserir em seus gestos, suas atitudes, seus discursos, sua aprendizagem, sua vida cotidiana”. Desse modo, cada um de nós é titular de um certo poder, um "poder microscópico", exercido pelos indivíduos e não sobre eles, produtivo, que provoca resistência e mudança, e não unicamente negativo no sentido da repressão. Essas relações de poder promovem mudanças que não estão absolutamente ligadas às mudanças institucionais no nível das formas centralizadas do Estado. Destacando que o exercício do poder está ligado ao saber e às verdades, "não é possível que o poder se exerça sem o saber, não é possível que o saber não engendre poder" (FOUCAULT, 1989, p. 231), ao mesmo tempo em que o exercício do poder resulta nos regimes de verdades de cada sociedade.

Guacira Louro (1995, p. 119) destaca: “o que Foucault nos propõe é o entendimento do poder como uma relação e não como algo que se possui". Ela também chama atenção para a necessidade de estarmos atentas/os ao fato de que os processos de construção de gênero, raça e classe não são resultado de uma imposição unilateral pela sociedade, tendo em vista que a sociedade não constitui um todo homogêneo com capacidade de impor algo diretamente e sem que haja resistência. As atitudes, práticas, valores, habilidades, comportamentos, conhecimentos socialmente transmitidos ou inculcados pelas diferentes instâncias sociais não são simplesmente "internalizados" pelos sujeitos, sem que esses "aceitem, rejeitem, contestem, adaptem, enfim sem que, de múltiplas formas, eles participem desse processo" (LOURO, 1995, p. 108). Faz-se necessário pensar que as múltiplas técnicas utilizadas pelas diversas instituições sociais, para "adestrar corpos e almas, sem dúvida disciplinaram e moldaram esses sujeitos, reprimiram gestos, suprimiram expressões; também construíram posturas, comportamentos, movimentos e produziram consciência do próprio corpo" (LOURO, 1995, p. 123). Entre essas múltiplas técnicas e mecanismos utilizados na construção do gênero, destacamos aqui os materiais didáticos, especialmente os livros, que são confeccionados a partir de determinadas perspectivas e concepções de gênero, e que pode influenciar a construção dos conhecimentos das/os estudantes.

Segundo Guacira Louro, a invisibilidade das mulheres foi produzida a partir de múltiplos discursos que caracterizaram a esfera do privado, o mundo doméstico, como o 
verdadeiro universo da mulher. No entanto, as diferenças biológicas não justificam a desigualdade social, "mas é a forma como essas características são apresentadas ou valorizadas, aquilo que se diz ou pensa sobre elas é que vai construir, efetivamente, o que é feminino ou masculino em uma dada sociedade e em um dado momento histórico" (LOURO, 1995, p. 25). Contudo, ela não nega a biologia, pois ressalta que as construções sociais e históricas são produzidas sobre os corpos, sobre as características sexuais. Louro (1995, p. 27) também observa que as representações sobre homens e mulheres são diversas, pois "as concepções de gênero diferem não apenas entre as sociedades ou momentos históricos, mas no interior de uma dada sociedade ao se considerar os diversos grupos (étnicos, religiosos, raciais, de classe) que a constituem". Nesse sentido, a autora reflete que "as diferentes instituições e práticas sociais são constituídas pelos gêneros e são, também, constituintes dos gêneros", ou seja, da mesma forma que o gênero constitui as identidades dos sujeitos, é também constituído por eles, é recíproco, relacional, se fazendo incessantemente e em constante mudança.

Segundo Joana Maria Pedro, a palavra gênero começou a ser usada no contexto das lutas do movimento das mulheres e do feminismo de segunda onda, que buscavam uma explicação para a subordinação das mulheres, reivindicando a categoria Mulher. No entanto:

Mulheres negras, índias, mestiças, pobres, trabalhadoras, muitas delas feministas, reivindicaram uma "diferença" - dentro da diferença. Ou seja, a categoria "mulher", que constituía uma identidade diferenciada da de "homem", não era suficiente para explicá-las. Elas não consideravam que as reivindicações as incluíam. Não consideravam como fez Betty Friedan na "Mística Feminina", que o trabalho fora do lar, à carreira, seria uma "libertação". Estas mulheres há muito trabalhavam dentro e fora do lar. O trabalho fora do lar era para elas, apenas, uma fadiga a mais. Além disso, argumentavam, o trabalho "mal remunerado" que muitas mulheres brancas de camadas médias reivindicavam como forma de satisfação pessoal, poderia ser o emprego que faltava para seus filhos, maridos e pais. Todo este debate fez ver que não havia a "mulher", mas sim as mais diversas "mulheres", e que aquilo que formava a pauta de reivindicações de umas, não necessariamente formaria a pauta de outras. Afinal, as sociedades possuem as mais diversas formas de opressão, e o fato de ser uma mulher não a torna igual a todas as demais. Assim, a identidade de sexo não era suficiente para juntar as mulheres em torno de uma mesma luta. Isto fez com que a categoria "Mulher" passasse a ser substituída, em várias reivindicações, pela categoria "mulheres", respeitando-se então o pressuposto das múltiplas diferenças que se observavam dentro da diferença. E, mais: que a explicação para a subordinação não era a mesma para todas as mulheres, e nem aceita por todas. (PEDRO, 2005, p. 82). 
Evidenciadas as diferenças entre as mulheres, a noção de Universal foi questionada. Assim como Homem não era sujeito universal, Mulher também não, o que remete à questão principal do porquê de as mulheres em diferentes sociedades serem submetidas à autoridade masculina, nas mais diversas formas e diversos graus.

Para Joana Maria Pedro e Rachel Soieht (2007, p. 284), "nas Ciências Humanas a disciplina História é certamente a que mais tardiamente apropriou-se dessa categoria, assim como da própria inclusão de 'mulher' ou de 'mulheres' como categoria analítica na pesquisa histórica". Sobre isso, as autoras observam que esse atraso se deveu ao caráter universal atribuído ao sujeito da história, representado pela categoria "Homem", pois dizia-se que ao falar dos homens, as mulheres estariam incluídas - premissa já amplamente questionada e não mais aceita por boa parte de historiadores/as.

Desse modo, é possível concluir que o gênero como categoria analítica possibilitou a reflexão sobre as hierarquias nas relações entre homens e mulheres, e do aspecto relacional entre ambos, ou seja, de que nenhuma compreensão de qualquer um dos dois poderia existir através de um estudo que os considerasse totalmente em separado, aspecto essencial para "descobrir a amplitude dos papéis sexuais e do simbolismo sexual nas várias sociedades e épocas, achar qual o seu sentido e como funcionavam para manter a ordem social e para mudá-la" (PEDRO; SOIEHT, 2007, p. 288).

O uso do gênero como categoria analítica é compatível com o uso de outras categorias, entretanto, o silêncio sobre outras formas de opressão permanecia, exigindo a reelaboração do discurso e das práticas políticas do feminismo. De acordo Sueli Carneiro (2019), a trajetória das mulheres negras no interior do movimento feminista revelou a insuficiência teórica e prática política para integrar diferentes expressões do feminino, construídos em sociedades multirraciais e pluriculturais. Tal autora demonstra que grupos de mulheres negras e indígenas, por exemplo, "possuem demandas específicas que, essencialmente, não podem ser tratadas, na essência, sob a rubrica da questão de gênero se esta não levar em conta as especificidades que definem o ser mulher neste ou naquele caso" (CARNEIRO, 2019, p. 274).

O protagonismo das mulheres negras exigiu o reconhecimento da diversidade e desigualdade existente entre as mulheres, descortinando o viés eurocentrista do feminismo brasileiro, que universalizava os valores de uma cultura para o conjunto das mulheres. Também colocaram em relevo o peso do racismo e da discriminação racial na desigualdade de gênero e intragênero, promovendo mudanças de perspectiva no movimento feminista, observadas na nova Plataforma Política Feminista aprovada em Brasília, em junho de 2002. 
Mas, como destaca Djamila Ribeiro (2018, p. 51), "bem antes disso, mulheres negras já desafiavam o sujeito mulher determinado pelo feminismo", lembrando que, enquanto as mulheres brancas lutavam pelo direito ao voto, as mulheres negras lutavam para ser consideradas pessoas. Diante do silenciamento do feminismo com relação às mulheres negras, e da trajetória dos movimentos de mulheres que, ao ignorar uma opressão de umas em detrimento de outras, ou hierarquizá-las, enfraqueceu e atrasou a campanha pelos direitos das mulheres, o "feminismo negro emergiu como um esforço teórico e prático de demonstrar que raça, gênero e classe são inseparáveis nos contextos sociais em que vivemos" (DAVIS, 2016, p. 21). Para Angela Davis, uma das contradições refere-se à luta pelo direito ao trabalho no espaço público:

[...] as mulheres negras sempre trabalharam mais fora de casa do que suas irmãs brancas. $\mathrm{O}$ enorme espaço que o trabalho ocupa hoje na vida das mulheres negras reproduz um padrão estabelecido durante os primeiros anos da escravidão. Como escravas, essas mulheres tinham todos os outros aspectos de sua existência ofuscada pelo trabalho compulsório. (DAVIS, 2016, p. 17)

Davis aponta que certos estereótipos pretendiam "capturar a essência do papel da mulher negra durante o período de escravidão" a partir do mito de que a típica escrava era uma trabalhadora doméstica, cozinheira, arrumadeira ou mammy (babá), quando na realidade a maioria das mulheres escravizadas trabalhavam na lavoura. No trabalho, a opressão das mulheres era idêntica à dos homens, mas, além do sofrimento no trabalho, as mulheres eram vítimas de abuso sexual, entre outros maus-tratos bárbaros que só poderiam ser infligidos a elas. Nesse sentido, a autora destaca que, "enquanto as punições mais violentas impostas aos homens consistiam em açoitamentos e mutilações, as mulheres eram também açoitadas, mutiladas e estupradas" (DAVIS, 2016, p. 20). Além de servir como reprodutoras para ampliação da força de trabalho escrava, não tinham nenhum direito legal sobre suas filhas e filhos, que poderiam ser vendidos a qualquer momento e em qualquer idade.

Ao analisar o contexto dos Estados Unidos, Davis evidencia que a equiparação ocupacional das mulheres negras com o serviço doméstico perdurou mais até a entrada do país na Segunda Guerra Mundial, quando o trabalho feminino manteve a economia de guerra em funcionamento e mais de 400 mil mulheres negras deram adeus para seus trabalhos domésticos. Aponta ainda que, embora tenham colaborado de forma inestimável para a campanha antiescravagista, as mulheres brancas quase nunca conseguiam compreender a complexidade da situação da mulher escravizada. As vivências durante a escravidão, o 
trabalho pesado ao lado de seus companheiros, a igualdade no interior da família, a resistência, os açoitamentos e estupros sofridos, as encorajavam a desenvolver certos traços de personalidade, que as diferenciavam da maioria das mulheres brancas.

A partir do feminismo negro norte-americano surge o conceito de interseccionalidade na teoria feminista, cunhado por Kimberlé Crenshaw para casos jurídicos em defesa dos direitos das mulheres, explicando que:

A garantia de que todas as mulheres sejam beneficiadas pela ampliação da proteção dos direitos humanos baseados no gênero exige que se dê atenção às várias formas pelas quais o gênero intersecta-se com uma gama de outras identidades e ao modo pelo qual essas intersecções contribuem para a vulnerabilidade particular de diferentes grupos de mulheres desconhecida e precisa, em última análise, ser construída a partir do zero (CRENSHAW, 2002, p. 174).

Além do gênero, então, é necessário utilizar outras lentes para leitura social e considerar as diferenças de classe, raça, cor, etnia, religião, geração, origem nacional, orientação sexual, entre outras que constituem uma associação de sistemas múltiplos de subordinação. A interseccionalidade é uma conceituação do problema que busca capturar as consequências estruturais e dinâmicas da interação entre dois ou mais eixos da subordinação. Ela trata especificamente da forma pela qual a discriminação cria desigualdades básicas, além de tratar da forma como ações e políticas específicas geram opressões que fluem ao longo de tais eixos discriminatórios, constituindo aspectos dinâmicos ou ativos do desempoderamento (CRENSHAW, 2002, p. 177).

Importante considerar o contexto da heterossexualidade compulsória, como apresenta Adrienne Rich (2010). O poder dominador exercido pelos homens sobre as mulheres provoca uma negação e apagamento da sexualidade delas. A idealização romântica da heteronormatividade serve para controlar o trabalho e produção das mulheres, por meio do casamento, da maternidade e da cafetinagem. São diversos os mecanismos de controle, investidas até de palavras positivas como cuidado e amor, mas que se traduzem em proibições de modos de vestir, ir e falar.

Segundo Rich (2010, p. 26), ao retirar as mulheres de amplas áreas de conhecimento e de realizações culturais da sociedade, desestimulando seu protagonismo nas ciências, na tecnologia e em outras profissões valorizadas como sendo "masculinas", excluem-se e discriminam as mulheres. Além disso, a autora destaca que a indústria pornográfica também tem contribuído para disseminar e reforçar a representação das mulheres como uma 
"mercadoria sexual a ser consumida pelos homens", pois relaciona sexualidade e violência, coloca a mulher em situação de submissão e humilhação, e retira sua autonomia sexual.

Diante da violência e desigualdade de gênero na sociedade, o tema deveria ser um dos eixos estruturantes da formulação de políticas públicas no país. Esse contexto demonstra a necessidade de analisar, compreender e propor encaminhamentos para o enfrentamento dessa realidade. Nesse sentido, decidimos analisar as relações de gênero na História ensinada a partir do livro didático, que na maioria das vezes ainda é a principal fonte de estudo para professores/as e estudantes nos seus processos de aprendizagem.

\section{Relações de gênero no ensino de história: livros didáticos e o Guia}

Thais Nivia de Lima e Fonseca (1999) reforça que o livro didático não é objeto descolado das estruturas de dominação, pois é um dos elementos difusores, não apenas do conhecimento histórico, mas também de uma determinada memória, que ao lado de outras fontes, apresentam-se como parte essencial de uma determinada formulação política e de um determinado contexto cultural.

O livro didático e a educação formal não estão descolados do contexto político e cultural e das estruturas de dominação, sendo, muitas vezes, instrumentos utilizados na legitimação de sistemas de poder, além de representativos de universos culturais específicos. Sua elaboração não parte, exclusivamente, de interesses pré-estabelecidos, mas incorpora as concepções de história e os sistemas de valores dos autores e de seu tempo. Atuam, na verdade, como mediadores entre concepções e práticas políticas e culturais, tornando-se parte importante da engrenagem de manutenção de determinadas visões de mundo e de história. Junto à arte, à imprensa e outros meios de comunicação, colaboram para a circulação e a apropriação de determinadas idéias, valores e comportamentos (FONSECA, 1999, p. 204).

Para Helenice Rocha (2017), o livro didático, caracterizado como portador de conhecimentos disciplinares para uso escolar, é resultado de um processo complexo de apropriação de conhecimento de diversas áreas, que se assemelha parcialmente com o conhecimento disciplinar de natureza acadêmica, entendido como um conhecimento de referência e que está entre os mais visados pela crítica pública. Contudo, a narrativa escolar da história, também é portadora de uma memória social com valor formativo, pois narram essa História "destacando aspectos que podem bonificar a sociedade de que tratam e silenciar sobre aspectos que representariam demérito, por meio dos temas, enfoques, sujeitos, eventos e 
processo escolhidos para serem narrados" (ROCHA, 2017, p. 14), constitui objeto de disputa social pela narrativa válida.

Bittencourt contextualiza o processo de renovação do ensino de História no Brasil desde a década de 1980, quando foram propostos novos currículos de História, constatando que houve mudanças significativas em direção à formação de uma cidadania democrática após a LDB de 1996 e do PCN de 1998. Houve ainda um reforço com a implementação das Leis 10.639/2003 e 11.645/2008, decorrentes das lutas dos movimentos de mulheres, negros, indígenas e LGBT. Então, os livros didáticos estão há décadas no centro de muitos debates.

Refletir sobre a emergência do gênero, considerando a lente da interseccionalidade e a importância do livro didático no processo de aprendizagem histórica, possibilita o desenvolvimento de um olhar crítico sobre os apagamentos e invisibilidades das mulheres no material didático de História, e a compreensão do protagonismo feminino na luta pela equidade de direitos.

O livro didático, por mais que se pretenda homogeneizador do saber e por vezes utilizado como instrumento de memorização, pode ser controverso, pois a leitura permite diferentes apropriações.

A leitura é sempre apropriação, invenção, produção de significados [...]. Apreendido pela leitura, o texto não tem modo algum - ou ao menos totalmente - o sentido que lhe atribuiu seu autor, seu editor ou seus comentadores. Toda história da leitura supõe, em seu princípio, esta liberdade do leitor que desloca e subverte aquilo que o livro the pretende impor. Mas esta liberdade leitora não é jamais absoluta. Ela é cercada por limitações derivadas das capacidades, convenções e hábitos que caracterizam, em suas diferenças, as práticas de leitura (CHARTIER, 1999, p. 77).

A diversidade de leituras se dá a partir dos diferentes processos de aprendizagem, das escolaridades mais ou menos longas, do domínio mais ou menos seguro da cultura escrita, entre outras. Lana Siman e Luisa Andrade compreendem que ler é produzir sentidos, a partir das relações que o leitor estabelece entre as informações do texto e seus conhecimentos anteriores, oriundos de suas experiências plurais com outros textos e contextos socioculturais. Nessa perspectiva, "ler um texto é subverter a ordem prevista para o mundo do leitor, ler um texto é dialogar com as vozes ali presentes nas palavras e na materialidade de que é feito o texto" (ANDRADE; SIMAN, 2013, p. 2013).

Sobre a trajetória da História Ensinada no Brasil, Bittencourt apresenta os confrontos em torno de seus objetivos, inicialmente voltados para a formação de uma elite política e 
econômica caracterizada por uma prática de exclusão dos diferentes grupos sociais. essa autora destaca que a existência da História escolar no Brasil inicialmente deveu-se, sobretudo, ao seu papel formador da identidade nacional, e que as propostas atuais se preocupam mais em "identificar o indivíduo como pertencente ao sistema capitalista globalizado" (BITTENCOURT, 2015, p. 18).

Para Maria Auxiliadora Schmidt e Marlene Cainelli, o ensino de história deve colocar objetivos a disposição dos/as estudantes, para que eles/as tenham a possibilidade de se orientar a partir da experiência histórica. Mas para que o conhecimento histórico possa orientar os problemas da vida prática, não pode vir com um sentido pronto e acabado, com conteúdos predefinidos, sem levar em conta o contexto e os sujeitos envolvidos no processo de aprendizagem. O Ensino de História deve "possibilitar construir com os alunos novas questões diante de conteúdos/temas postos pela historiografia. Aprender história é discutir evidências, levantar hipóteses, dialogar com os sujeitos, os tempos e os espaços históricos" (SCHMIDT; CAINELLI, 2009, p. 20).

O Guia de livros didáticos de História do PNLD de 2018 (BRASIL, 2017), elaborado com o objetivo de auxiliar na escolha das coleções que serão adquiridas e distribuídas pelo Estado nos próximos três anos, enfatiza os princípios destacados acima, mostrando para as professoras e professores no momento da escolha dos livros, o grau de alinhamento das obras, com os pontos necessários à sua aprovação destacados no edital. O Guia contém informações produzidas por dezenas de profissionais de todas as regiões brasileiras envolvidos na avaliação das obras inscritas. A instituição responsável pela avaliação do PNLD de 2018 foi a Universidade Federal de Sergipe (UFS), selecionada pela Chamada Pública n. 04/2016 (DOU 22/04/2016). Metade dos/as avaliadores/as é sorteada do Banco de Avaliadores ${ }^{1}$, e a outra metade é de escolha da Instituição de Ensino Superior (IES) responsável, e passam por capacitação no que diz respeito às prescrições do edital, aos itens da ficha de avaliação elaborada com base no edital, aos critérios eliminatórios comuns a todas as áreas e também aos critérios específicos ao componente curricular História.

A primeira questão apresentada pelo Guia é quem ou o que orienta a construção do currículo para o Ensino Médio. Especialistas apontam que são, por um lado as Orientações Curriculares Nacionais para o Ensino Médio (1999) e, por outro, a Matriz de Referência de Ciências Humanas (2009), que fundamentam a construção dos itens do Exame Nacional do

\footnotetext{
$1 \quad$ A partir de 2016, metade dos avaliadores passaram a ser sorteados de um Banco de Avaliadores, que consiste num cadastro nacional de profissionais habilitados a integrar equipes de avaliação pedagógica de obras didáticas, literárias, outros materiais de leitura e conteúdo de recursos educacionais digitais.
} 
Ensino Médio (ENEM), destacando ainda que há quem deposite nos livros didáticos aprovados pelo PNLD o papel de indutor do conteúdo a ser ensinado em sala de aula. No entanto, o Guia afirma que não há um denominador comum a respeito dos fins e dos conteúdos a serem prescritos para a etapa. Isso ocorre porque o Brasil não possui um currículo nacional oficial, ao menos até a divulgação da BNCC do Ensino Médio.

De acordo com o texto introdutório do Guia, as políticas listadas anteriormente não estão forçosamente hierarquizadas. Elas foram produzidas em momentos diferentes e sob demandas também várias, e que mesmo se houvesse uma normativa homogênea, as práticas docentes e discentes não seriam as mesmas. Esclarece ainda que a distribuição de livros a milhões de estudantes do Ensino Médio se deu em paralelo às políticas de ampliação da escolarização básica, gratuita e obrigatória dessa etapa de ensino, estabelecida entre 2009 e 2013, como a resolução que define Diretrizes Curriculares Nacionais para o Ensino Médio (Resolução n. 2/2012/CNE) e as leis que asseguram acesso "a todos os interessados ao Ensino Médio público" (Lei n. 12.061/2009).

De acordo com o Guia (BRASIL, 2017), de modo geral, o PNLD reconfigurou o manual do professor como instrumento de formação continuada e também contribuiu para ampliar o conhecimento em relação aos direitos humanos, fomentando a mudança de ênfase do ensinar História para o aprender História, e que os Guias também estimularam autores/as e editores/as a qualificarem a abordagem sobre combate à homofobia, as singularidades culturais dos povos indígenas e afrodescendentes, as identidades juvenis e as especificidades da aprendizagem histórica para o Ensino Médio. Com o mesmo objetivo, os Guias noticiaram a ampliação do espaço concedido à História da África, à imagem da mulher, à compreensão da historicidade da cidadania em toda a obra e à problematização dos conhecimentos prévios dos estudantes, pontos estes considerados mudanças positivas que indicam a importância do PNLD como política de Estado (Decreto lei n. 7084/2010).

Na seção de visão geral apresentada pelo Guia sobre cada coleção avaliada, a Coleção História Sociedade e Cidadania é descrita como uma obra cujos princípios éticos, em sua historicidade, são respeitados, destacando-se a abordagem da figura das mulheres enquanto sujeitos da história e sua presença em diferentes espaços sociais, além de evidenciar a questão da diversidade étnico-racial e a compreensão da pluralidade cultural e social do país. A terceira parte do manual do professor apresenta, segundo o Guia, a discussão sobre a cultura afro, indígena e relações de gênero. Sobre o componente curricular, destaca que a ideia do passado como reconstrução, a atenção a historicidade dos conceitos, a relatividade do 
conhecimento produzido pela Ciência da História, e a sua necessidade de reescrita encontramse presentes nas seções, nos textos base e nas atividades.

Nas subseções, de acordo com o Guia a coleção apresenta atividades de comparação entre fontes e busca-se mostrar que as diferentes formas e versões de construção do passado, compreendendo-o como passível de mudanças e que explicações históricas são influenciadas pelo presente. Destaca que na parte referente a formação cidadã são enfatizadas a diversidade da experiência histórica, a pluralidade social e a variedade cultural e étnico-racial nas relações sociais.

Ainda conforme o Guia, a obra retrata as mulheres como sujeitos históricos nas seções, nos textos, nas imagens, e nas atividades, demonstrando suas lutas e contribuições para a construção de uma sociedade menos desigual. O projeto gráfico apresenta imagens contextualizadas e acompanhadas de atividades de leitura e interpretação, referenciando sua condição de fonte para a produção do conhecimento histórico (ter legenda, ano de produção, curiosidades ou outros elementos que auxiliem o estudante na percepção dos detalhes da época, ano de produção, etc. (BRASIL, 2017, p. 70).

No final da resenha, na parte intitulada "sala de aula", afirma que os princípios éticos são respeitados na coleção, principalmente com relação ao tratamento aos diversos grupos sociais como os afrodescendentes e as mulheres, aparecendo como atrizes e atores históricos ao longo dos três volumes da obra.

A visão geral da Coleção História - das Cavernas ao Terceiro Milênio, exposta pelo Guia, apresenta que a obra incentiva uma postura de compromisso com sistemas democráticos de organização da sociedade e de repúdio as injustiças e a toda forma de preconceito. $\mathrm{Na}$ análise da obra, destaca que o Manual do Professor apresenta uma proposta voltada para a autonomia docente que afirma que o saber histórico deve estar vinculado às questões da atualidade para dotar de sentido e interesse os conteúdos curriculares. Quanto ao componente curricular História na coleção, compreende-se a escrita da História como um processo social e cientificamente produzido, que desempenha funções na sociedade. Segundo o Guia, no que diz respeito à formação cidadã, a coleção proporciona debates sobre os aspectos contemporâneos da superação de toda forma de violência, em especial a que se faz contra a mulher, uma vez que apresenta diversos exemplos da discriminação e violência simbólica e física que sofreram mulheres e outras minorias ao longo da história. Ao mesmo tempo, elas são apresentadas como protagonistas dos acontecimentos e processos históricos, buscando 
conscientizar os estudantes acerca da necessidade do respeito mútuo e do convívio pacífico entre os diversos indivíduos e grupos sociais (BRASIL, 2017, p. 91).

De acordo com a avaliação apresentada no Guia, a coleção, promove educação e cultura em direitos humanos, afirmando-se os direitos de crianças, adolescentes e idosos. A abordagem da temática das relações étnico-raciais visa a construção de uma sociedade antirracista, solidária, justa e igualitária, tanto nos textos didáticos e complementares quanto nas diversas seções, boxes e exercícios. $\mathrm{Na}$ obra também se abordam frequentemente as temáticas de gênero, tendo como horizonte a proposta de uma sociedade equitativa e não sexista.

Em resumo, com base no Guia, podemos dizer que a Coleção História, Sociedade e Cidadania, aprovada no PNLD de 2018, avança em vários aspectos com relação à aprovada no PNLD de 2015. O chamado "manual do professor" contendo uma parte extra direcionado as professoras e aos professores tem uma parte, intitulada cidadania, etnia e gênero, na qual apresenta a discussão sobre as temáticas afro, indígena e de gênero, não mencionada pelo Guia de 2015. Quanto à formação cidadã, apresenta que:

[...] retratam-se as mulheres como sujeitos históricos nas seções, nos textos, nas imagens e nas atividades, demonstrando suas lutas e contribuições para a construção de uma sociedade menos desigual. Assim, auxilia-se no entendimento da mulher como agente participativo e responsável pelas mudanças históricas, na superação da violência e na discussão dos papéis sociais tradicionalmente atribuídos ao gênero feminino. (BRASIL, 2017, p. 69).

Nesse sentido, apresenta avanço principalmente ao destacar a necessidade de superação da violência e a discussão dos papéis sociais tradicionalmente atribuídos ao gênero feminino.

Quanto à Coleção História: das Cavernas ao Terceiro Milênio aprovada no PNLD de 2018, de maneira sintética podemos destacar que, conforme o Guia, a obra proporciona debate sobre os aspectos contemporâneos da superação de toda forma de violência, em especial a que se faz contra a mulher, uma vez que apresenta diversos exemplos da discriminação e violência simbólica e física que sofreram mulheres e outras minorias ao longo da história. Ao mesmo tempo, elas são apresentadas como protagonistas dos acontecimentos e processos históricos, o que representa um avanço com relação a mesma coleção quando aprovada em 2015, ao exemplificar os tipos de violência cometidas contra as mulheres e ao explicitar como proposta, "uma sociedade equitativa e não sexista" (BRASIL, 2017, p. 91). 
A proposta de Joan Scott de incluir o gênero como categoria de análise histórica, de investigação sobre como, e a partir de quais significados as hierarquias de gênero são construídas e legitimadas, possibilita identificar e alterar as desigualdades entre homens e mulheres na sociedade, concebendo a História como produtora do saber de gênero a partir de construções que, apesar de naturalizadas, podem ser construídas de outras formas. Para isso, é necessário reforçar a emergência dos Estudos de Gênero na formação das professoras e dos professores de História, para instrumentalizá-los/las a desconstruir estereótipos de gênero, raça e classe, pois não basta que os Guias apontem um avanço na produção editorial dos livros didáticos, é preciso que haja um engajamento docente para efetivação dessas práticas antimachistas e anti-racistas.

\section{Considerações finais}

As desigualdades sociais apontadas no início desse artigo evidenciam o quanto as mulheres estão em desvantagem aos homens na sociedade. Mais ainda se forem negras, indígenas e de camadas mais pobres economicamente. A invisibilidade de determinadas raças ou classes aumentam o esquecimento em relação à importância de que as mulheres sempre estiveram no cenário da História, igualmente com os homens, mesmo que fazendo coisas diferentes.

Tantas conquistas (mercado de trabalho e cidadania - grandes exemplos) e as mulheres continuam à margem da História. Não é diferente o atraso nos livros didáticos, mesmo depois de tantos avanços das pesquisas acadêmicas, da epistemologia feminista e das recomendações de avaliadores/as desses materiais.

Procuramos apresentar as definições analíticas da categoria gênero nos fundamentos da historiadora Joan Scott. Foi preciso, no entanto, recorrer às feministas negras como Sueli Carneiro, Djamila Ribeiro, Angela Davis e Kimberle Crenshaw para se compreender melhor o quanto se agravam os silenciamentos de gênero quando se trata de mulheres negras e indígenas. Há ainda um longo caminho a se percorrer para conquistarmos a tão desejada equidade.

\section{Referências}

ALMEIDA, Silvio Luiz de. O que é racismo estrutural? Belo Horizonte: Letramento, 2018. 
ANDRADE, Luísa Teixeira; SIMAN, Lana Mara de C. Livro didático de história lido em sala de aula: uma prática de leitura dentre outras possíveis. In: GALZERANI, Maria Carolina Bolvério; BUENO, João Batista Gonçalves; PINTO Jr., Arnaldo. Paisagens da pesquisa contemporânea sobre o livro didático de História. Jundiaí: Paco Editorial; Campinas: Centro de Memória: UNICAMP, 2013. p. 181-208.

BITTENCOURT, Circe Maria Fernandes. O saber histórico na sala de aula. São Paulo: Contexto, 2015.

BRAICK, Patrícia Ramos; MOTA, Myriam Becho. História: das cavernas ao terceiro milênio. 4. ed. São Paulo: Editora Moderna, 2016. 3 v.

BRASIL. Ministério da Educação. Secretaria de Educação Básica. PNLD 2018: história guia de livros didáticos. Ensino Médio. Brasília, 2017. Disponível em: https://www.fnde.gov.br/index.php/programas/programas-do-livro/pnld/guia-do-livrodidatico/item/11148-guia-pnld-2018.

BRASIL. Ministério da Educação. Conselho Nacional de Educação. Câmara de Educação Básica. Resolução n. 2, de 30 de janeiro de 2012. Define Diretrizes Curriculares Nacionais para o Ensino Médio. Brasília, 2012. Disponível em: http://portal.mec.gov.br/index.php? option=com_docman\&view=download\&alias=9864-rceb002-12\&Itemid=30192 .

BRASIL. Ministério da Educação. Decreto n. 7084, de 27 de janeiro de 2010. Dispõe sobre os programas de material didático e dá outras providências. Diário Oficial da União: seção 1, Brasília, DF, p. 3, 27 jan. 2010. Edição extra. Disponível em: https://www.planalto.gov.br/ccivil_03/_ato2007-2010/2010/decreto/d7084.htm.

BRASIL. Lei n. 12.061, de 27 de outubro de 2009. Altera o inciso II do art. 4 e o inciso VI do art. 10 da Lei n. 9.394, de 20 de dezembro de 1996, para assegurar o acesso de todos os interessados ao ensino médio público. Diário Oficial da União: seção 1, Brasília, DF, p. 1, 28 out. 2009. Disponível em: https://www.planalto.gov.br/ccivil_03/_ato20072010/2009/lei/112061.htm.

BRASIL. Lei n. 11.645, de 10 de março de 2008. Altera a Lei n. 9.394, de 20 de dezembro de 1996, modificada pela Lei n. 10.639, de 9 de janeiro de 2003, que estabelece as diretrizes e bases da educação nacional, para incluir no currículo oficial da rede de ensino a obrigatoriedade da temática "História e Cultura Afro-Brasileira e Indígena". Diário Oficial da

União: seção 1, Brasília, DF, p. 1, 11 mar. 2008. Disponível em: https://legislacao.presidencia.gov.br/atos/?

tipo $=$ LEI\&numero $=11645 \&$ ano $=2008 \&$ ato $=$ de6QTS61UNRpWTcd 2 .

BRASIL. Lei n. 10.639, de 9 de janeiro de 2003. Altera a Lei n. 9.394, de 20 de dezembro de 1996, que estabelece as diretrizes e bases da educação nacional, para incluir no currículo oficial da Rede de Ensino a obrigatoriedade da temática "História e Cultura Afro-Brasileira", e dá outras providências. Diário Oficial da União: seção 1, Brasília, DF, p. 1, 10 jan. 2003. Disponível em: http://www.planalto.gov.br/ccivil_03/leis/2003/110.639.htm.

BOULOS JÚNIOR, Alfredo. História: sociedade \& cidadania. 2. ed. reformulada. São Paulo: FTD, 2016. $4 \mathrm{v}$.

CARNEIRO, Sueli. Mulheres em movimento: contribuições do feminismo negro. In: HOLLANDA, Heloisa B. (org.) Pensamento feminista brasileiro: formação e contexto. Rio de Janeiro: Bazar do tempo, 2019. p. 271-289. 
CERQUEIRA, D. et al. Atlas da violência 2019. Brasília: Ipea; FBSP, 2019. Disponível em: http://www.ipea.gov.br/portal/images/stories/PDFs/relatorio institucional/190605 atlas da v iolencia 2019.pdf.

CHARTIER, Roger. A aventura do livro: do leitor ao navegador. Tradução Reginaldo de Moraes. São Paulo: UNESP, 1999.

CHOPPIN, Alain. História dos livros didáticos e das edições didáticas: sobre o estado da arte. Educação e Pesquisa, São Paulo, v. 30, n. 3, p. 549-566, set./dez. 2004. Disponível em: http://www.revistas.usp.br/ep/article/view/27957/29729.

CRENSHAW, Kimberlé. Documento para o encontro de especialistas em aspectos da discriminação racial relativos ao gênero. Revista Estudos Feministas, Florianópolis, v. 10, n. 1 p. 171-188, $1^{\circ}$ sem. 2002. Disponível em: https://periodicos.ufsc.br/index.php/ref/article/view/S0104-026X2002000100011/8774.

DAVIS, Angela. Mulheres, raça e classe. São Paulo: Boitempo, 2016.

FONSECA, Thais Nivia de Lima e. Livro didático de História: lugar de memória e formador de identidades. In: ANAIS DO SIMPÓSIO NACIONAL DA ASSOCIAÇÃO NACIONAL DE HISTÓRIA, 20., 1999, Florianópolis. Anais [...]. São Paulo: Humanitas; FFLCH-USP; ANPUH, $1999 . \quad$ p. 203-212. 0 Disponível https://anpuh.org.br/index.php/documentos/anais/category-items/1-anais-simposios-anpuh/21snh20?start $=20$.

FOUCAULT, Michel. Microfísica do poder. 8. ed. Rio de janeiro: Graal, 1989.

FRANCO, Aléxia; ZAMBONI, Ernesta. Apropriação docente dos livros didáticos de História. In: GALZERANI, Maria Carolina Bolvério; BUENO, João Batista Gonçalves; PINTO Jr., Arnaldo. Paisagens da pesquisa contemporânea sobre o livro didático de História. Jundiaí: Paco Editorial; Campinas: Centro de Memória: UNICAMP, 2013.

HOOKS, Bell. Olhares negros: raça e representação. São Paulo: Elefante, 2019.

INSTITUTO BRASILEIRO DE GEOGRAFIA E ESTATÍSTICA - IBGE. Estatísticas de gênero: indicadores sociais das mulheres no Brasil. Rio de Janeiro, 2016.

LOURO, Guacira Lopes. Gênero, história e educação: construção e desconstrução. Revista Educação e Realidade, Porto Alegre, v. 20, n. 2, p. 101-132, 1995. Disponível em: https://seer.ufrgs.br/educacaoerealidade/article/view/71722/40669.

PEDRO, Joana Maria. Traduzindo o debate: o uso da categoria gênero na pesquisa histórica. História, São Paulo, v. 24, n. 1, p. 77-98, 2005. Disponível em: https://www.scielo.br/pdf/his/v24n1/a04v24n1.pdf.

PEDRO, Joana Maria, SOIEHT, Rachel. A emergência da pesquisa da história das mulheres e das relações de gênero. Revista Brasileira de História, São Paulo, v. 27, n. 54, p. 281-300, 2007. Disponível em: https://www.scielo.br/pdf/rbh/v27n54/a15v2754.pdf.

RIBEIRO, Djamila. Quem tem medo do feminismo negro? São Paulo: Companhia das Letras, 2018.

RICH, Adrienne. Heterossexualidade compulsória e existência lésbica. Revista Bagoas: estudos gays, gênero e sexualidade, Natal, v. 4, n. 5, p. 17-44, 2010. Disponível em: https://periodicos.ufrn.br/bagoas/article/view/2309/1742.

ROCHA, Helenice. O livro didático de História em análise: a força da tradição e transformações possíveis. In: ROCHA, Helenice; REZNIK, Luis; MAGALHÃES, Marcelo de 
Souza. Livros didáticos de história: entre políticas e narrativas. Rio de Janeiro: FGV Editora, 2017.

SCHMIDT, Maria Auxiliadora; CAINELLI, Marlene. Ensinar história. São Paulo: Scipione, 2009.

SCOTT, Joan Wallack. Gênero: uma categoria útil de análise. Revista Educação e Realidade, Porto Alegre, v. 20, n. 2, p. 71-99, jul./dez. 1995. Disponível em: https://www.seer.ufrgs.br/educacaoerealidade/article/viewFile/71721/40667.

SCOTT, Joan Wallack. Prefácio a Gender and politics of history. Cadernos Pagu, Campinas, n. $3, \quad$ p. $11-27, \quad 1994 . \quad$ Disponível https://periodicos.sbu.unicamp.br/ojs/index.php/cadpagu/article/view/1721/1705. 